\title{
Desempenho de cordeiros alimentados com dietas contendo sal forrageiro de espécies vegetais xerófitas ${ }^{1}$
}

\author{
Geógenes da Silva Gonçalves ${ }^{2}$, Gabriel Jorge Carneiro de Oliveira ${ }^{3}$, Soraya Maria Palma \\ Luz Jaeger ${ }^{3}$, Ronaldo Lopes Oliveira ${ }^{4}$, Jamille Oliveira Campos ${ }^{5}$, Letícia Santos Rezende ${ }^{6}$ \\ ${ }^{1}$ Projeto financiado pela FAPESB - Fundação de Amparo à Pesquisa do Estado da Bahia. \\ 2 Programa de Pós-graduação em Ciências Agrárias, Centro de Ciências Agrárias, Ambientais e Biológicas da UFRB, Cruz das Almas - BA. \\ CEP: $44.380-000$. \\ ${ }^{3}$ Centro de Ciências Agrárias, Ambientais e Biológicas da UFRB, Cruz das Almas - BA, CEP: 44.380-000. \\ ${ }^{4}$ Escola de Medicina Veterinária da UFBA, Salvador - BA. CEP: 40.170-110. \\ 5 PROMEV, Av. Alberto Passos, 453, Cruz das Almas - BA. CEP: 44.380-000 \\ ${ }^{6}$ Centro de Ciências Agrárias, Ambientais e Biológicas da UFRB, Cruz das Almas - BA, CEP: 44.380-000.
}

RESUMO - Este trabalho foi realizado com o objetivo de avaliar o uso de sal forrageiro sobre os consumos de sal forrageiro (CSF) e de feno de capim-pangola (Digitaria decumbens) e os consumos de matéria seca (MS), proteína bruta (PB), fibra em detergente neutro (FDN), hemicelulose (HCEL), lignina e água (AGU), além do ganho de peso diário (GPD) e da conversão alimentar de cordeiros em confinamento. Os sais forrageiros foram compostos de farelos de fenos (90\%) das dicotiledôneas, sal mineral (5\%) e milho triturado (5\%). Utilizaram-se 30 animais machos não-castrados, mestiços Santa Inês, distribuídos em delineamento inteiramente casualizado, com seis tratamentos (sal mineral; sal forrageiro de leucena, Leucaena leucocephala; sal forrageiro da parte aérea de mandioca, Manihot esculenta; sal forrageiro de feijão-bravo, Macroptilium bracteatum; sal forrageiro de barriguda, Ceiba samauma; e sal forrageiro de quipé, Piptadenia moniliformis), cada um com cinco repetições. Os sais forrageiros de leucena e da parte aérea de mandioca promoveram melhores resultados de desempenho, ganhos de pesos totais e conversão alimentar, o que evidencia o potencial dessas forrageiras para formulação de sal forrageiro, utilizado na suplementação de dietas para cordeiros em confinamento.

Palavras-chave: confinamento, conversão alimentar, dicotiledôneas, ovinos

\section{Performance of lambs fed diets with fodder salt composed of xerophilic plants species}

\begin{abstract}
This study was to evaluate the use of fodder salt (salt and dicotyledon hay mix) on daily intake of fodder salt (IFS) and pangola (Digitaria decumbens) hay, and intakes of dry matter (DM), crude protein (CP), neutral detergent fiber (NDF), hemicellulose (HCEL), lignin and water (AGU), in addition to daily weight gain (ADG) and feed conversion tatio of lambs in confinement. Fodder salts were compound by dicotyledon hay meal (90\%), mineral salt (5\%) and ground maize (5\%). Thirty non-castrated male animals, crossbred Santa Inez, were distributed to a completely randomized design, with six fodder salts (mineral salt, fodder salts of: leucaena, (Leucaena leucocephala); aerial part of cassava, (Manihot esculenta); bean bravo (Macroptilium bracteatum); barriguda, (Ceiba samauma); quipé (Piptadenia moniliformis)], each with five replications. Fodder salts of leucaena and aerial part of cassava promoted better performance results, which evidence the potential of this forages in the formulation of fodder salts, used in the supplementation of diet for lambs in confinement.
\end{abstract}

Key Words: containment, dicotyledon, feed conversion, sheep

\section{Introdução}

A principal limitação ao uso das pastagens no semiárido brasileiro é a estacionalidade produtiva, causada principalmente por fatores climáticos, como baixa umidade e irregularidades das precipitações durante os períodos de seca. Além do aspecto quantitativo, a lignificação da parede celular e a redução do teor protéico e da digestibilidade da planta, causadas pela maturação da forragem, são responsáveis pela redução no valor nutritivo desses pastos.

O consumo da forragem é um dos principais fatores que influenciam o desempenho animal, pois, segundo Mertens (1994), determina 60 a $90 \%$ das variações de desempenho, enquanto apenas 10 a $40 \%$ dessas variações 
estão relacionadas à digestibilidade dos componentes nutritivos.

Tosi (1999) afirma que, mesmo em épocas desfavoráveis, os animais podem ter seu crescimento contínuo, desde que recebam suplementação alimentar estratégica que permita ganho moderado, porém importante para o crescimento. No caso de dietas desbalanceadas, com reduzida disponibilidade de nitrogênio ou ricas em fibra em detergente neutro (FDN), o suprimento de proteína degradada no rúmen é limitante para o crescimento microbiano. Segundo Cavalcante et al. (2005), o uso de leguminosas na composição dos suplementos aumenta de forma significativa o desempenho animal sem afetar o equilíbrio do ecossistema (utilização de forragens da caatinga).

O sal forrageiro, uma mistura de sal mineral com feno de forrageira dicotiledônea, pode ser também mais uma alternativa de suplementação para esses animais. Silva (2006) alimentou cordeiros com sal forrageiro de leucena, gliricídia e da parte aérea de mandioca e observou que o sal forrageiro promoveu maior desempenho em comparação ao feno de capim-pangola (controle).

Este trabalho foi realizado com o objetivo avaliar o uso de diferentes dicotiledôneas para produção de sal forrageiro. Avaliaram-se os consumos de sal forrageiro, de feno de capim-pangola e dos componentes matéria seca, proteína bruta, fibra em detergente neutro, hemicelulose, lignina e água, além do ganho de peso e da conversão alimentar, em cordeiros mestiços da raça Santa Inês em confinamento.

\section{Material e Métodos}

O experimento foi desenvolvido em área com tipo climático semi-árido, temperatura média anual de $25^{\circ} \mathrm{C}$, período chuvoso de abril a junho e pluviosidade média anual de 600 a 800 mm (Centro de Estatística e Informações, 1994).

Utilizaram-se 30 animais machos não-castrados, mestiços de Santa Inês, com 4 meses de idade e $22 \pm 2,56 \mathrm{~kg}$ de peso corporal, confinados em área de chão batido, coberta com palhas de ouricuri. Os animais foram distribuídos em baias individuais contendo comedouro, bebedouro e vasilhame com sal mineral ou sal forrageiro.

Todos os animais receberam feno de capim-pangola (Digitaria decumbens, Stent.) à vontade. O experimento teve início em 12 de janeiro e término em 23 de março de 2006, com duração de 70 dias (14 dias de adaptação e 56 dias de período experimental). Antecipadamente à instalação do experimento, todos os animais foram vermifugados e inoculados com vacina polivalente contra clostridiose e vacina contra raiva, obedecendo aos procedimentos técnicos veterinários.

Os animais foram pesados em balanças específicas para ovinos e identificados por brincos e colares. As pesagens foram realizadas a cada sete dias, às 7 h, após jejum de alimentos por 15 horas.

Os sais forrageiros utilizados foram compostos de farelos de fenos (90\%) de leucena (Leucaena leucocephala), da parte aérea de mandioca (Manihot esculenta) (SFPAM), de feijão-bravo (Macroptilium atropurpureum), de barriguda (Ceiba samaum) e de quipé (Piptadenia moniliformis) mais sal mineral (5\%) e milho triturado na proporção de $5 \%$ com finalidade de aumentar a palatabilidade das misturas (Tabela 1).

Os fenos das dicotiledôneas foram obtidos a partir dos ramos tenros com folhas, desidratados ao sol sobre lonas de polietileno. O diâmetro dos caules do capim-pangola, de leucena, da parte aérea da mandioca, de feijão bravo, barriguda e quipé foram, respectivamente, $0,6 \pm 1,62 ; 0,8 \pm 1,56$; $0,7 \pm 2,18 ; 0,8 \pm 2,23 ; 1,6 \pm 2,12 ;$ e $0,7 \pm 2,17 \mathrm{~mm}$.

O sal mineral utilizado foi uma mistura comercial específica para ovinos, com a seguinte composição: cálcio, $140,00 \mathrm{~g} / \mathrm{kg}$; fósforo, 65,00 g/kg; enxofre, $15,00 \mathrm{~g} / \mathrm{kg}$; magnésio, 15,00 g/kg; zinco, 3.500,00 mg/kg; manganês, $3.000,00 \mathrm{mg} / \mathrm{kg}$; iodo, $60,00 \mathrm{mg} / \mathrm{kg}$; selênio, $10,00 \mathrm{mg} / \mathrm{kg}$; cobalto, 100,00 mg/kg; vitamina A, 50.000,00 UI/Kg; flúor (máx.), 650,00 mg/kg; sódio, 153,00g/kg.

Com o intuito de evitar a seletividade dos animais, os fenos das forrageiras foram moídos e peneirados em malha fina e misturados ao sal mineral e ao milho triturado.

O delineamento experimental utilizado foi o inteiramente casualizado (DIC), com seis tratamentos e cinco repetições, descritos a seguir: sal mineral (testemunha); sal forrageiro de leucena; sal forrageiro da parte aérea da mandioca; sal forrageiro de feijão-bravo; sal forrageiro de barriguda e sal forrageiro de quipé.

Assim como o feno de capim-pangola, os sais forrageiros e/ou o sal mineral foram pesados diariamente e administrados à vontade. As sobras diárias do sal forrageiro, do sal mineral e do feno de capim-pangola foram recolhidas, pesadas e subtraídas do total fornecido, a fim de quantificar o alimento consumido pelos animais, individualmente.

Os teores de matéria seca (MS) e proteína bruta (PB) foram determinados de acordo com métodos da AOAC (1990); os de fibra em detergente neutro (FDN), fibra em detergente ácido (FDA) e lignina, pela técnica descrita por Van Soest et al. (1991), no Laboratório de Nutrição Animal da Escola de Medicina Veterinária da Universidade Federal da Bahia; e o de hemicelulose foi obtido pela diferença entre a FDN e a FDA. 
Tabela 1 - Composição bromatológica (\% da MS) dos ingredientes das dietas experimentais

\begin{tabular}{|c|c|c|c|c|c|c|}
\hline Ingrediente & MS (\%) & PB (\%) & FDN (\%) & FDA (\%) & Hemicelulose (\%) & Lignina $(\%)$ \\
\hline Feno de pangola ${ }^{1}$ & 93,14 & 7,02 & 79,04 & 35,49 & 43,55 & 9,27 \\
\hline Feno de leucena ${ }^{1}$ & 90,38 & 27,00 & 37,32 & 20,32 & 17,00 & 7,70 \\
\hline Feno de da parte aérea da mandioca ${ }^{1}$ & 90,07 & 22,68 & 51,97 & 36,18 & 15,79 & 16,54 \\
\hline Feno de barriguda ${ }^{1}$ & 90,27 & 9,48 & 54,59 & 38,94 & 15,65 & 11,75 \\
\hline Feno de quipé ${ }^{1}$ & 89,47 & 15,70 & 57,19 & 37,50 & 19,69 & 23,67 \\
\hline Milho moído 2 & 87,82 & 8,89 & 11,06 & 5,24 & 5,82 & 1,79 \\
\hline
\end{tabular}

${ }_{1}^{1}$ Análises realizadas no laboratório de Nutrição Animal da Escola de Veterinária da UFBA.

2 Segundo Valadares Filho et al. (2006).

Avaliaram-se os consumos de sal forrageiro, de feno de capim-pangola, de matéria seca, proteína bruta, fibra em detergente neutro, hemicelulose e lignina, a conversão alimentar (relação entre o consumo de MS e o ganho de peso: $\mathrm{CA}$ = consumo diário de MS/ganho de peso diário) e o ganho de peso total.

\section{Resultados e Discussão}

As médias dos consumos de sal forrageiro pelos animais alimentados com os sais à base de leucena e da parte aérea de mandioca foram maiores que as obtidas com os demais sais e não diferiram entre si (Tabela 2). Esse resultado pode estar relacionado principalmente ao maior consumo de proteína bruta das dietas contendo sal forrageiro de leucena e sal forrageiro da parte aérea de mandioca, que permite aumento da fermentação microbiana, promovendo maior aproveitamento da FDN e esvaziamento ruminal, que, por sua vez, estimula o consumo e melhora o desempenho animal (Berchielli et al., 2006). Os valores destas médias foram próximos ao encontrado por Silva et al. (2006), que observaram em ovinos consumos de sal forrageiro de leucena e de sal forrageiro da parte aérea de mandioca de 739,49 e 483,61 g/dia, respectivamente.

Os consumos de feno de capim-pangola pelos animais alimentados com sal forrageiro de barriguda e de quipé foram maiores que os obtidos com o fornecimento dos sais forrageiros à base de leucena, da parte aérea de mandioca e de feijão-bravo. É provável que os maiores consumos de feno de capim-pangola observados quando os cordeiros receberam os sais forrageiros de barriguda e quipé tenham sido promovidos pela menor aceitabilidade das dicotiledôneas utilizadas na confecção desses sais forrageiros, o que induziu ao menor consumo de matéria seca dos fenos das dicotiledôneas e ao maior consumo de matéria seca do feno de capim-pangola.

Os consumos de matéria seca pelos animais alimentados com sal forrageiro à base de leucena e da parte aérea de mandioca podem estar relacionados ao aumento da participação desses sais forrageiros na dieta. Apesar de terem sido confeccionados com forrageiras tropicais, que, em razão da baixa digestibilidade, podem limitar o consumo de matéria seca (Church, 1993), os sais forrageiros de leucena e da parte aérea de mandioca promoveram maiores consumos de matéria seca em relação aos demais e não diferiram entre si. O aumento de consumo de matéria seca, segundo Mallmann et al. (2006), pode estar associado ao suprimento de nitrogênio em quantidades adequadas à manutenção da atividade microbiana. Também de acordo com Mertens (1994), o aumento de consumo de matéria seca está associado positivamente aos níveis de proteína bruta e às concentrações de fibra em detergente neutro. Os valores de consumo de matéria seca foram próximos ao preconizado pelo NRC (1985), de $1.000 \mathrm{~g} /$ dia para cordeiros com peso vivo de $20 \mathrm{~kg}$ para ganho de peso de $64 \mathrm{~g} / \mathrm{dia}$.

Nos animais com a alimentação à base de sal forrageiro de leucena e sal forrageiro da parte aérea de mandioca consumos de matéria seca foram próximos ao encontrado por Silva et al. (2006), que avaliaram o consumo de matéria seca utilizando leucena e parte aérea de mandioca com ovinos mestiços da raça Santa Inês e encontraram consumos de 803,12 e 943,47 g/dia, respectivamente.

Os consumos de proteína bruta pelos cordeiros com alimentação à base de sal forrageiro de feno de leucena e da parte aérea de mandioca foram maiores que os obtidos com os demais sais. As médias de consumo de proteína bruta nesses animais foram superiores ao preconizado pelo NRC (1985) para ovinos de baixo potencial genético, de $112 \mathrm{~g} /$ dia para animais com $20 \mathrm{~kg}$ de peso vivo. Esse resultado pode estar relacionado principalmente à aceitabilidade das dicotiledôneas com maiores teores de proteína bruta, que, de acordo com Souza et al. (2000), promove maior equilíbrio na fermentação microbiana, que estimula o consumo e aumenta a digestibilidade melhorando o desempenho dos animais.

Os valores de consumo de proteína bruta pelos animais que receberam sal forrageiro de leucena e da parte aérea de 
Tabela 2 - Consumos diários de sal forrageiro (CSF), de feno de pangola (CFP) e de nutrientes em cordeiros alimentados com sais forrageiros

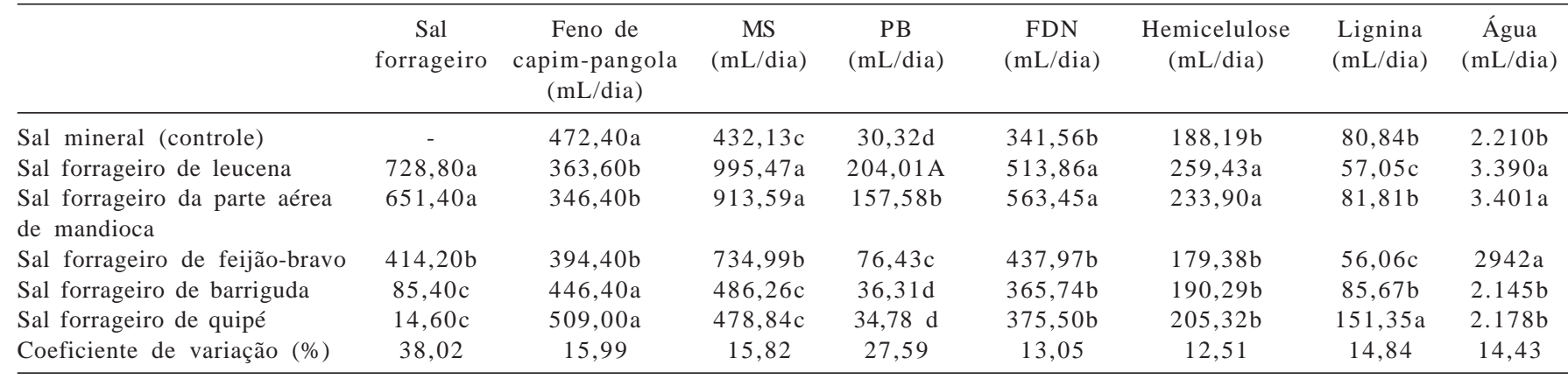

Médias seguidas de mesma letra nas colunas não diferem estatisticamente $(P<0,05)$ pelo teste Scott e Knott.

mandioca foram superiores aos encontrados por Silva et. al. (2006), que avaliaram o consumo de proteína bruta utilizando sal forrageiro de leucena e da parte aérea de mandioca com ovinos mestiços da raça Santa Inês e encontraram consumos de 122,69 e 113,71 g/dia, respectivamente. Os valores foram, no entanto, inferiores ao encontrado por Silva et al. (2007), que avaliaram o consumo de proteína bruta do feno de maniçoba em cordeiros Santa Inês, com média de 28,62 de peso vivo na proporção de $80 \%$ de feno na dieta, e encontraram consumo de 220,54 g/dia. Esses resultados podem estar relacionados ao aproveitamento das forragens pelos animais e à categoria de peso vivo de $22 \pm 2,56 \mathrm{~kg}$ utilizada no experimento.

A ingestão de fibra em detergente neutro pelos ovinos que receberam sal forrageiro de leucena e da parte aérea de mandioca foi maior que a observada com o fornecimento de sal mineral e com os sais forrageiros de feijão-bravo, barriguda e quipé. O maior consumo de fibra em detergente neutro pode estar associado aos níveis desta fibra na dieta e aos consumos de matéria seca e proteína bruta entre os animais alimentados com os sais forrageiros de leucena e da parte aérea de mandioca, pois provavelmente promoveu maior digestibilidade da fibra em detergente neutro por fornecer aos microrganismos do rúmen maior quantidade de nitrogênio (NRC, 1985). Segundo Mertens (1982), o nível de FDN está relacionado ao consumo, em virtude da relação desta fibra e o espaço ocupado pelos volumosos. Assim, se a ingestão é limitada pelo espaço do trato gastrintestinal, a ingestão de alimentos com alto teor de FDN é restringida. Em dietas com baixa concentração de FDN e alto nível energia, a demanda fisiológica é o fator que limita a ingestão (Mertens, 1983).

Os maiores consumos de hemicelulose foram obtidos com os sais à base de leucena e da parte aérea de mandioca. Esses resultados podem estar associados à maior ingestão de matéria seca e de sal forrageiro. A mais rápida degrabilidade da hemicelulose promove maior digestibilidade da parede celular e conseqüente esvaziamento do rúmen, além de redução do tempo de permanência da fração fibrosa no trato gastrointestinal, o que permite maior ingestão de matéria seca (Berchielli et al., 2006).

De acordo com Van Soest (1994) e Eastridge (1997), a hemicelulose é a fração da parede celular que possui mais rápida degrabilidade, o que possibilita maior consumo. Embora o sal forrageiro de quipé tenha maior quantidade de hemicelulose, em comparação aos demais sais forrageiros, também apresentou maior quantidade de lignina, o que provavelmente diminuiu a digestibilidade e o consumo da mistura.

O consumo de lignina pelos animais que receberam o sal forrageiro de quipé foi o maior (Tabela 2), o que pode estar relacionado ao fato de o quipé apresentar maiores concentrações de lignina (Tabela 1). A quantidade de lignina presente no quipé pode ter determinado o menor consumo de matéria seca em comparação aos consumos dos demais sais forrageiros, pois, segundo Silva et al. (2007), a lignina é um composto fenólico da parede celular considerado indigestível e sua maior concentração pode ser uma das possíveis causas dos baixos valores de digestibilidade da parede celular.

Os maiores consumos de água foram observados nos cordeiros alimentados com os sais forrageiros de leucena, da parte aérea de mandioca e de feijão-bravo. Provavelmente os maiores consumos de água foram ocasionados pelos maiores consumos de matéria seca e proteína bruta. Segundo o NRC (1985), os consumos voluntários de água pelos ovinos estão relacionados aos consumos de matéria seca, proteína bruta e sal mineral das dietas. De acordo com Berchielli et al. (2006), o consumo de água pelos ruminantes é influenciado pelo consumo de proteína bruta, pois resulta em maior demanda de água, decorrente do incremento calórico proveniente do processo digestivo da proteína. 
Os valores de ganho de peso diário (Tabela 3) foram inferiores ao encontrado por Silva et al. (2006), que, utilizando sais forrageiros das mesmas dicotiledôneas, observaram ganhos de peso diário de 109,52 e 85,19 g/dia, respectivamente, e por Santana (2005), que encontrou valor médio de ganho de peso diário de 93,82 g/dia utilizando sal forrageiro composto de resíduo desidratado de sisal.

Resultados próximos os encontrados neste experimento foram verificados por Bade (2004), que utilizou 25 e $75 \%$ de farelo de palma forrageira em substituição a raspa de mandioca na alimentação de ovinos e observou ganhos de 78,00 e $80,00 \mathrm{~g} / \mathrm{dia}$, respectivamente. Resultados superiores (174,64 g/dia), foram observados por Strada et al. (2006) ao fornecerem suplemento a ovinos deslanados criados em pastagem de Digitaria decumbens com o sal forrageiro de leucena (SFL).

O ganho de peso diário dos cordeiros alimentados com sal forrageiro de feijão-bravo foi de 48,57 g/dia, valor que não difere estatisticamente dos obtidos com sal forrageiro de barriguda e quipé e com a mistura mineral, de 25,71 g/dia; 21,42 e 20,71 g/dia. Santos (2003) encontrou ganho de peso de $40 \mathrm{~g} /$ dia com uso exclusivo de capim-elefante à vontade para ovinos em confinamento. Silva et al. (2006), utilizando feno de capim-pangola e sal mineral, encontraram ganho de peso de 45,24 g/dia em estudo com ovinos em confinamento.

Não houve efeito significativo $(\mathrm{P}<0,05)$ das dietas sobre a conversão alimentar na fase de confinamento, que apresentou valor médio de 14,25 . No entanto, foi observada tendência a maior conversão alimentar, o que se deve, provavelmente, ao efeito dos sais forrageiros sobre o consumo de outras dietas (Tabela 3).

Os dados obtidos neste trabalho para conversão alimentar foram maiores que os 9,6; 8,4 e 7,0 registrados por Alves et al. (2003) em ovinos Santa Inês terminados em confinamento com dietas com diversos níveis de energia. Garcia et al. (2000) também verificaram índice de conversão alimentar de

Tabela 3 - Ganho de peso diário (GPD) e conversão alimentar (CA) de cordeiros alimentados com sais forrageiros

\begin{tabular}{lcc}
\hline & $\begin{array}{c}\text { Ganho de peso } \\
\text { diário (g) }\end{array}$ & $\begin{array}{c}\text { Conversão } \\
\text { alimentar }\end{array}$ \\
\hline Sal mineral (controle) & $20,71 \mathrm{~B}$ & 8,51 \\
Sal forrageiro de leucena & $74,64 \mathrm{~A}$ & 15,0 \\
Sal forrageiro de parte & $85,00 \mathrm{~A}$ & 10,8 \\
aérea de mandioca & & \\
Sal forrageiro de feijão-bravo & $48,57 \mathrm{~B}$ & 16,3 \\
Sal forrageiro de barriguda & $25,71 \mathrm{~B}$ & 19,1 \\
Sal forrageiro de quipé & $21,42 \mathrm{~B}$ & 15,8 \\
Média & 46,01 & 14,25 \\
CV (\%) & 47,46 & 62,91 \\
\hline
\end{tabular}

Médias seguidas de mesma letra nas colunas não diferem estatisticamente $(P<0,05)$ pelo teste de Scott e Knott.
4,31 em cordeiros mestiços Santa Inês. Preziuso et al. (1999) relataram índices de conversão de 4,52; 4,77 e 4,61 para cordeiros alimentados com uma ração sem adição de óleo e duas rações contendo $5 \%$ de óleo de milho.

A menor eficiência inicial de utilização da energia dietética e a maior conversão alimentar verificadas neste trabalho têm sido freqüentemente relatadas na literatura (Ryan, 1990; Hogg, 1991) como resultado do menor conteúdo energético do alimento sobre o ganho de peso e da maior exigência de energia de mantença dos animais, em decorrência da menor digestibilidade em comparação aos outros alimentos em experimento.

Neste estudo, embora tenha afetado o desempenho, a dieta não influenciou a conversão alimentar, uma vez que o ganho de peso total é uma medida direta e a conversão alimentar é uma medida indireta (kg MS ingerida/ganho de peso total), o que resulta na diluição das médias.

\section{Conclusões}

Sais forrageiros de leucena e da parte aérea de mandioca promoveram consumos, ganhos de pesos totais e conversão alimentar melhores que os obtidos com sais forrageiros de feijão-bravo, barriguda e quipé, o que comprova o potencial dessas dicotiledôneas para utilização como sal forrageiro para suplementação a cordeiros.

\section{Literatura Citada}

ASSOCIATION OF OFFICIAL ANALYTICAL CHEMISTS - AOAC. Official methods of analysis. 15.ed. Virginia: 1990. 1117p. ALVES, K.S.; CARVALHO, F.F.R.; VÉRAS, A.S.C. Níveis de energia em dietas para ovinos Santa Inês: Desempenho. Revista Brasileira de Zootecnia, v.32, n.6, p.1937-1944, 2003.

BADE, P.L. Consumo voluntário e desempenho de ovinos recebendo dietas com diferentes níveis de farelo de palma forrageira em substituição à raspa de mandioca. Salvador: Escola de Medicina Veterinária, 2004. 45p. Dissertação (Mestrado em Produção Animal) - Escola de Medicina Veterinária, 2004.

BAHIA. Informações básicas dos municípios baianos. Salvador: Centro de Estatística e Informações, 1994. v.2. 440p.

BERCHIELLI, T.T.; RODRIGUEZ, N.M.; OSÓRIO NETO, E. et al. Nutrição de ruminantes. Jaboticabal: Funep, 2006. 583p.

CAVALCANTE, M.A.B.; PEREIRA, O.G.; VALADARES FILHO, S.C. Níveis de proteína bruta em dietas para bovinos de corte: consumo e digestibilidades total e parcial dos nutrientes. Revista Brasileira de Zootecnia, v.34, n.6, p.2200-2208, 2005.

CHURCH, C.D. El ruminante: fisiologia digestiva y nutrición. Zaragoza: Acribia, 1993. 645p.

EASTRIDGE, M.L. Fibra para vacas leiteiras. In: In: SIMPÓSIO SOBRE PRODUÇÃO ANIMAL, 9., 1997, Piracicaba. Anais... Piracicaba: Fundação de Estudos Agrários "Luiz de Queiroz", 1997. p.33-50.

GARCIA, I.F.F.; BONAGURIO, S.; PÉREZ, J.R.O. Desempenho e características de carcaça de cordeiros de diferentes cruzamentos. In: REUNIÃO ANUAL DA SOCIEDADE BRASILEIRA DE ZOOTECNIA, 37., 2000, Viçosa, MG. Anais...Viçosa, MG: Sociedade Brasileira de Zootecnia, 2000. (CD-ROM). 
HOOG, B.W. Compensatory growth in ruminants. In: PEARSON, A.M.; DUTSON, T.R. (Eds.) Growth regulation in farm animals: advance in meat science research. Corvallis Oregone: Elsevier, 1991. v.7, p.103-134.

MALLMANN, G.M.; PATINO, H.O.; SILVEIRA, A.L.F. et al. Consumo e digestibilidade de feno de baixa qualidade suplementado com nitrogênio não protéico em bovinos. Pesquisa Agropecuária Brasileira, v.41, n.2, p.331-337, 2006.

MERTENS, D.R. Regulation of forage intake. In: FAHEY JR., G.C. (Ed.) Forage quality, evaluation and utilization. Madison: American Society of Agronomy, 1994. p.450-493.

MERTENS, D.R. Using neutral detergent fiber to formulate dairy rations. In: NUTRITION CONFERENCE PROCESS GANT CONFERENCE FOR THE FEED INDUSTRY, 1982, Athens. Proceedings... Athens: University of Georgia, 1982. p.116-126.

MERTENS, D.R. Using neutral detergent fiber to formulate dairy rations and estimate the net energy content of feeds. In: CORNELL NUTRITION CONFERENCE, 1983, Ithaca. Proceedings... Ithaca: Cornell University, 1983. p.60-68.

NATIONAL RESEARCH CONCIL - NRC. Nutrient requirements of sheep. Washington, D.C.: National Academy Press, 1985. 99p.

PACKER, I.U.; HADDAD, C.M. Interrelações entre genética e nutrição de bovinos. In: PEIXOTO, A.M.; MOURA, J.C.; FARIA, V.P. et al. (Eds.) Nutrição de bovinos: conceitos básicos e aplicados. Piracicaba: Fundação de Estudos Agrários Luiz de Queiroz, 1995. p.515-526.

PREZIUSO, G.; RUSSO, C.; CASAROSA, L. et al. Effect of diet energy source on weight gain and carcass characterisitcs of lambs. Small Ruminant Research, v.33, n.3, p.9-15, 1999.

RYAN, W.J. Compensatory growth in the cattle and sheep. Nutrition Abstracts and Reviews (Series B), v.6, n.9, p.653-664, 1990.

SANTANA, P.F.A. Suplemento múltiplo e sal forrageiro à base de resíduo seco do desfibramento do sisal (Agave sisalana) para ovinocultura. Cruz das Almas: Universidade Federal da Bahia, 2005. 50p. Dissertação (Mestrado em Ciências Agrárias) - Universidade Federal da Bahia, 2005.

SANTOS, I.C.V. Avaliação de consumo de folhas de gliricídia (Gliricídia sepium (Jacq.) Walp) sobre o desempenho de ovinos da raça Santa Inês. Cruz das Almas: Universidade
Federal da Bahia, 2003. 44p. Dissertação (Mestrado em Ciências Agrárias) - Universidade Federal da Bahia, 2003.

SILVA, A.M.; OLIVEIRA, G.J.C.; JAEGER, S.M.P.L. et al. Consumo de sal forrageiro por ovinos deslanados em confinamento. Magistra, v.18, n.1, p.1-6, 2006.

SILVA, D.S.; CASTRO, J.M.C.; MEDEIROS, A.N. Feno de maniçoba em dietas para ovinos: consumo de nutrientes,digestibilidade aparente e balanço nitrogenado. Revista Brasileira de Zootecnia, v.36, n.5, p.1685-1690, 2007 (supl.)

SILVA, E.A. Teores de proteína bruta para bovinos alimentados com feno de tifton 85: consumo e digestibilidades total e parcial. Revista Brasileira de Zootecnia, v.36, n.1, p.237-245, 2007.

SILVEIRA, A.C.; DOMINGUES, C.A.C. Alimentação e conversão de bovinos puros e cruzados. In: PEIXOTO, A.M.; MOURA, J.C.; FARIA, V.P. et al. (Eds.) Nutrição de bovinos: conceitos básicos e aplicados. Piracicaba: Fundação de Estudos Agrários Luiz de Queiroz, 1995. p.291-320.

SOUZA, A.A.; ESPÍNOLA, G.B. Banco de proteína de leucena e guandu para suplementação de ovinos mantidos em pastagem de capim buffel. Revista Brasileira de Zootecnia, v.29, p.366-367, 2000.

STRADA, E.S.O.; OLIVEIRA, G.J.C.; JAEGER, S.M.P.L. et al. Efeito da suplementação com sal forrageiro de leucena (Leucaena leucocephala (Lam) de Wit) sobre desempenho e características de carcaça de ovinos deslanados em regime de pasto. Magistra, v.18, n.2, p.74-79, 2006.

TOSI, H. Suplementação mineral em pastagem. In: SIMPÓSIO SOBRE MANEJO DA PASTAGEM, 1999, Piracicaba. Anais.. Piracicaba: Fundação de Estudos Agrários Luiz de Queiroz, 1999. 159 p.

VALADARES FILHO, S.C.; MAGALHÃES, K.A.; ROCHA JR., V.R. et al. Tabelas brasileiras de composição de alimentos para bovinos. 2.ed. Viçosa, MG: Universidade Federal de Viçosa, 2006. 329p.

Van SOEST, J.P. Nutritional ecology of the ruminant. 2.ed. Cornell: Comstock Publishing Associates, 1994. 476p.

Van SOEST, P.J.; ROBERTSON, J.B.; LEWIS, B.A. et al. Methods for dietary fiber, and nonstarch polysaccharides in relation to animal nutrition. Journal of Dairy Science, v.74, p.3583-3597, 1991. 